\title{
Primary proximal urethral adenocarcinoma: Case report and brief review
}

\author{
Marcos Duarte Siosaki, MD; Roberto Dias Machado, MD; Ana Tarsila Fonseca Souza, MD; Wesley Justino \\ Magnabosco, MD; Alexandre Cesar Santos, MD; Fernando Zapparoli Gonçalves, MD; Fernando Coutinho \\ Pereira, MD; Carlos Flávio de Araújo Silva, MD; Eliney Ferreira Faria, MD
}

Hospital de Câncer de Barretos, São Paulo, Brasil

Cite as: Can Urol Assoc J 2013;7(7-8):e499-501. http://dx.doi.org/10.5489/cuaj.399

Published online July 2, 2013.

\section{Abstract}

Primary urethral cancer in females is rare. It has a poor prognosis. The published data on this topic are limited, composed mostly of small case series. This paper presents a case of an advanced adenocarcinoma of the urethra, intestinal type, treated with anterior exenteration.

\section{Introduction}

Primary urethral cancer in females is rare, with annual overall incidence rate of 1.5 million. ${ }^{1}$ It corresponds to $0.003 \%$ of all malignant tumours occurring in the female urogenital tract. $^{2}$

Most neoplasms of the female urethra are squamous cell carcinoma $(60 \%)$, followed by transitional cell carcinoma $(20 \%)$, adenocarcinoma $(10 \%)$, undifferentiated tumors $(8 \%)$ and melanoma $(2 \%){ }^{3}$

We report on a case of advanced proximal urethral carcinoma treated with surgical resection; the patient was initially diagnosed with a transitional cell type during clinical staging, but after surgical resection, the tumour was revealed as an adenocarcinoma.

\section{Case report}

A 62-year-old woman presented with a history of irritative voiding symptoms for 3 months, followed by decreased urinary stream and obstruction in the past 3 weeks requiring catheterization. No weight loss or hematuria was reported. During the physical exam, we found a bulky mass in the anterior vaginal wall and an ulcerated wound in this topography. No inguinal nodules were palpated.
An abdominal and thorax computerized tomography was scheduled for clinical staging evaluation. The radiological finding showed an expansive formation involving the urethra circumferentially around its whole path, measuring about $6.9 \times 5.1 \times 4.8 \mathrm{~cm}$. The lesion infiltrated the bladder floor and had close contact with the anterior vaginal wall (Fig. 1). No lymphadenomegaly was noted. There were no other findings in the thorax and upper abdomen.

During cystoscopy a vegetating lesion was seen in the left lateral wall of the urethra; a biopsy was therefore performed. No lesion was seen on urinary bladder. Histopathology showed a high-grade transitional cell carcinoma.

After staging, we opted for surgical resection. Anterior pelvic exenteration was performed with urethrectomy (Fig. 2), resection of anterior vaginal wall (Fig. 3) and pelvic lymphadenectomy. Urinary reconstruction was done according to Bricker urinary diversion and the vagina was reconstructed using a flap of its posterior wall. A pelvic drain was placed in the pelvis.

There were no complications in the postoperative period. Feeding was initiated on postoperative day 1 . The drain was removed on postoperative 3 and the patient was then discharged on the same day.

The final histopathology showed adenocarcinoma, intestinal type, of urethra invading anterior vaginal wall and bladder neck with free surgical margins, $6.0 \times 5.0 \times 4.0 \mathrm{~cm}$, with no lymph nodes or lymph-vascular involvement. The patient was at clinical stage 3, pT3N0M0, as per the American Joint Committee on Cancer. ${ }^{4}$

\section{Discussion}

The common symptoms of primary female urethral carcinoma are urethrorrhagia, urinary frequency, dysuria, urethral obstruction, focal tenderness and urinary tract infection. However, neither of these symptoms are diagnostic or pathognomonic; so, delayed diagnosis or misdiagnosis is 


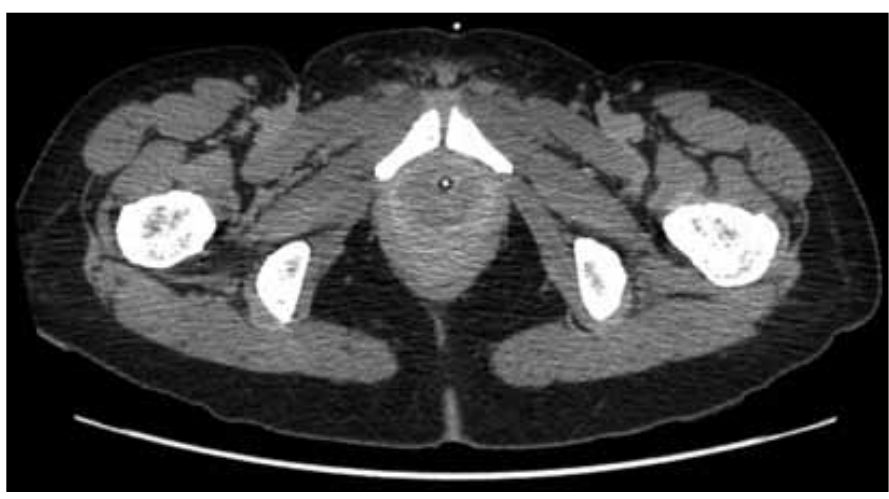

Fig. 1. A computerized tomography image of the lesion.

common. ${ }^{5}$ The median interval from onset of symptoms to diagnosis is about 4.5 months. ${ }^{1}$

The proximal one-third of the female urethra is lined by transitional epithelium, the distal two-thirds by stratified squamous epithelium. Accordingly, the histology of urethral tumours is generally consistent with the location. Tumours located distally or those involving the urethral meatus are typically squamous cell carcinoma. Tumours of the proximal urethra are commonly transitional cell carcinoma or adenocarcinoma. Adenocarcinoma occurring in the proximal female urethra can be in 2 broad classifications: clear cell adenocarcinoma or non-clear-cell adenocarcinoma. ${ }^{6}$

Spread of urethral carcinoma also follows the anatomic subdivision: the anterior/distal female urethra drains primarily to the inguinal nodes; the mid- and proximal urethra drains to the external iliac and deep pelvic lymph nodes. ${ }^{7}$ At presentation, one-third of patients have inguinal lymph node metastases and $20 \%$ have pelvic node involvement. ${ }^{3}$ Physical examination often reveals a palpable mass, but it may represent an inflammatory response. ${ }^{1}$

Female urethral carcinoma is rare, with a poor prognosis; it has a 5 - and 10 -year survival rate of $32 \%$ to $51 \%$ and $31 \%$ to $42 \%$, respectively. ${ }^{8}$ Data on this topic are limited, composed mostly of small case series.

Histologic type is also an independent prognostic variable along with tumour size. Champ and colleagues found that transitional cell carcinoma and adenocarcinoma histologic features are associated with shorter cancer specific survival than squamous cell carcinoma. ${ }^{8}$

Treatment policies vary among institutions, and this heterogeneity has been mirrored in published reports. Treatment is conventionally determined by tumour location, size and stage. Data have shown that lesions $<2 \mathrm{~cm}$ can be treated with surgical or radiotherapy monotherapy with potential cure. Similar data revealed a lack of cure for lesions $>4 \mathrm{~cm}$ when treated with radiotherapy, surgery alone or combined radiotherapy and nonexenterative surgery. ${ }^{8}$

DiMarco and colleagues concluded that treatment with local excision versus radical urethrectomy or anterior exenteration resulted in higher rates of local recurrence. ${ }^{9}$ Neither

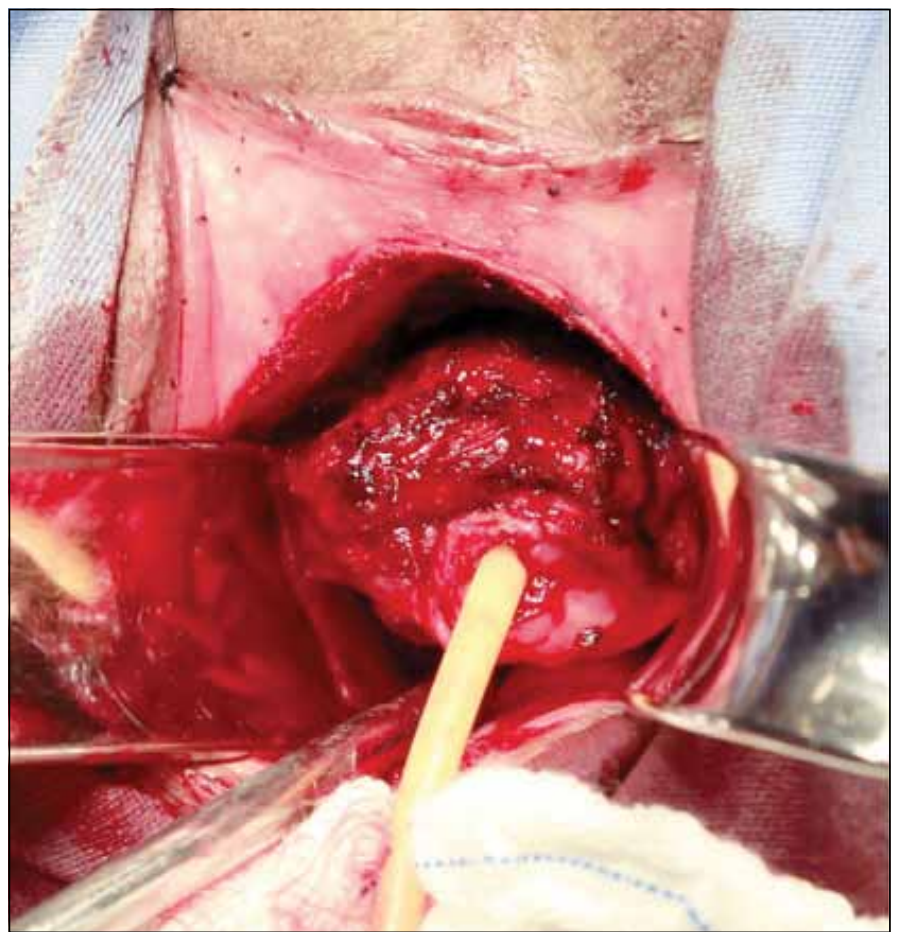

Fig. 2. Performing the urethrectomy.

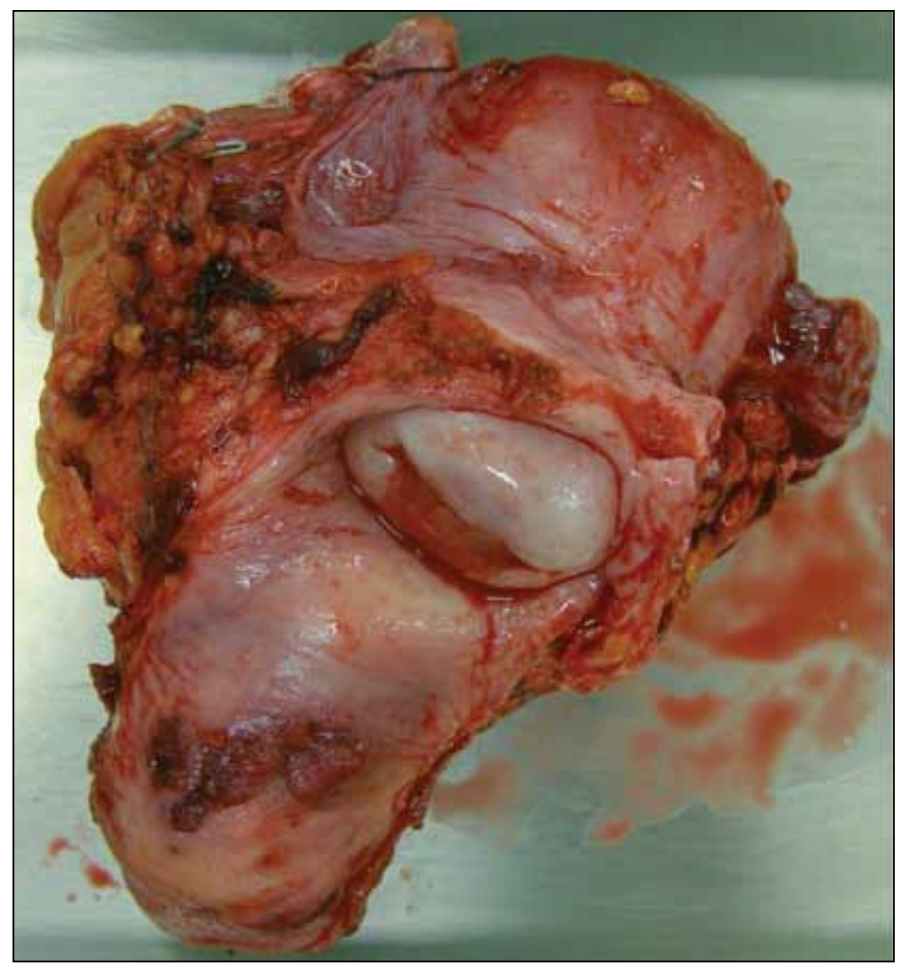

Fig. 3. After surgical resection showing the anterior vaginal wall.

adjuvant radiation nor chemotherapy was shown to improve rates of systemic recurrence or survival, but adjuvant radiation might decrease local recurrence. 


\section{Conclusion}

Urethral carcinoma is rare and the data available on this topic are limited. There are no guidelines for its management due to a lack of evidence. Adjuvant treatment may not improve survival rate, on the other hand recent papers have demonstrated improvements with neoadjuvant radiotherapy treatment mostly in local relapse-free survival.

Competing interests: None declared.

This paper has been peer-reviewed.

\section{References}

1. Derksen JW, Visser 0 , De La Rivière GB, et al. Primary urethral carcinoma in females: an epidemiologic study on demographical factors, histological types, tumour stage and survival. World J Urol 2013;31:14753 http://dx.doi.org/10.1007/s00345-012-0882-5. Epub 2012 May 22.
2. Reis $L 0$, Billis $A$, Ferreira $F T$, et al. Female urethral carcinoma: Evidences to origin from Skene's glands. Urol Oncol 2011;29:218-23. http://dx.doi.org/10.1016/j.urolonc.2009.03.019

3. Trabulsi EJ, Gomella LG. Cancer of the urethra and penis. In: DeVita VT, Lawrence TS, Rosenberg SA (eds). Cancer principles \& practice of oncology. Wolters Kluwer/Lippincott Williams \& Wilkins, Philadelphia; 2011:1272-9.

4. American Joint Committee on Cancer. Staging Resources. http://www.cancerstaging.org/staging/. Accessed June 17, 2013

5. Chen LP, Lin SJ, Fu TY, et al. Locally advanced female urethral adenocarcinoma of enteric origin: The role of adjuvant chemoradiation and brief review. Kaohsiung J Med Sci 2011;27:150-4. http://dx.doi.org/10.1016/.ikims.2010.12.009

6. Miller J, Karnes RJ. Primary clear-cell adenocarcinoma of the proximal female urethra: case report and review of the literature. Clin Genitourin Cancer 2008;6:131-3. http://dx.doi.org/10.3816/CGC.2008.n.022

7. Karnes RJ, Breau RH, Lightner DJ. Surgery for urethral cancer. Urol Clin N Am 2010;37:445-57. http://dx.doi.org/10.1016/i.ucl.2010.04.011

8. Champ CE, Hegarty SE, Shen X, et al. Prognostic factors and outcomes affer definitive treatment of female urethral cancer: a population-based analysis. Urology 2012;80:374-82. http://dx.doi.org/10.1016/.jurology.2012.02.058

9. DiMarco DS, DiMarco $\mathrm{CS}$, Zincke $\mathrm{H}$, et al. Surgical treatment for local control of female urethral carcinoma. Urol Oncol 2004;22:404-9. http://dx.doi.org/10.1016/S1078-1439(03)00174-1

Correspondence: Dr. Marcos Duarte Siosaki, Rua Alberto Segalla, 1-117. Apto 161-B. Edifíicio Horizonte. Bairro Infante Dom Henrique - CEP: 17012-634 - Bauru - São Paulo - Brasil; marcossiosaki@yahoo.com.br 